\title{
Selective forebrain fiber tract lesions implicate ventral hippocampal structures in tonic regulation of paraventricular nucleus corticotropin-releasing hormone (CRH) and arginine vasopressin (AVP) mRNA expression
}

\author{
James P. Herman a , William E. Cullinan ${ }^{\text {b }}$, Elizabeth A. Young ${ }^{\text {b }}$, Huda Akil ${ }^{\text {b }}$ \\ and Stanley J. Watson ${ }^{b}$ \\ "Department of Anatomy and Neurobiology. Unicersity of Kentucky Medical Center, Lexington, KY 40536-0084 (USA) \\ and "Mental Health Research Institute, Unic ersity of Michigan, 205 Zina Pitcher Place, Ann Arbor, MI 48109-0720 (USA)
}

(Accepted 12 May 1992)

Key words: Hippocampus; Parave, tricular nucleus; Fornix; Medial corticohypothalamic tract; Corticotropin-releasing hormone; ACTH; mRNA; In situ hybridization

The hippocampus appears to be involved in tonic regulation of the hypothalamo-pituitary-adrenocortical axis via interactions with corticotropin-releasing hormone (CRH) and arginine vasopressin (AVP)-containing neurons of the hypothalamic paraventricular nucleus (PVN). To further investigate the anatomical basis of such interactions, lesions were made to forebrain fiber tracts in position to communicate inhibitory information from the hippocampus to the PVN. Total fimbria-fornix transections (TFF) and lateral fimbria-fornix lesions (LFF) both significantly increased CRH mRNA levels in the medial parvocellular PVN, as assayed by semi-quantitative in situ hybridization histochemistry. Medial fimbria-fornix lesions or section of the medial corticohypothalamic traets (MCHT) did not influence CRH mRNA levels. The LFF group showed inereases in both AVP mRNA and ACTH secretion. whereus no other lesion was elfective in this regard. The results suggest: (1) hippocumpal efferents confering tonic inhibition of the HPA uxis probubly originnte in regions contributing to the lateral extent of the fornix, representing structures in the ventral subiculun and ventral extent of CAl: (2) projections from the hippocampus to the medial basal hypothatamus (travelling in the MCHT) are unlikely to affect HPA function; (3) hippoemmpus may influence the PVN CRH/AVP neuron at multiple levels, in that LFF and TFF lesions have difi rential effects on PVN AVP mRNA levels and ACTH secretion.

\section{INTRODUCTION}

The excitability of the hypothalamo-pituitaryadrenocortical (HPA) axis is primarily controlled by a discrete set of neurons localized to the medial parvo. cellular division of the hypothalamic paraventricular nucleus (PVN). Via synthesis and secretion of corticotropin-releasing hormone (CRH) and arginine vasopressin (AVP) this region is able to tightly regulate the release of ACTH by adenohypophysial corticotrophs, and subsequently tune the excitation of glucocorticoid release by the adrenal cortex ${ }^{1}$. The ability of this discrete set of neurons to affect ACTH release is susceptible to both short-term and long-term negative feedback by glucocorticoid hormones, the end-point of the HPA cascade ${ }^{16}$.

While the negative feedback effects of glucocorticoids on the HPA axis are well documented, precisely how this information is communicated to the medial parvocellular PVN neurons responsible for HPA activation is presently poorly understood. A local site of steroid negative feedback on the CRH neuron is suggested by studies demonstrating normalization of adrenalectomy-induced up-regulation of $\mathrm{CRH}$ and AVP peptide expression in medial parvocellular neurons following implants of solid steroid pellets into the region of the PVN ${ }^{17,33}$ (presumably mediated via endogenous type-2 glucocorticoid receptors ${ }^{41}$ ). On the Correspondence: J.P. Herman, Department of Anatomy and Neurobiology, University of Kentucky Medical School, Lexington, KY 40536-0084,
USA. Fax: (1) (606) 258-5946. 
other hand, recent data from our laboratory indicates that deafferentation of the hypothalamic PVN induces both CRH and AVP mRNA expression in parvocellular PVN neurons in the face of normal steroid levels ${ }^{15}$, suggesting an important interplay between nะural circuits and ACTH secretagogue production at the level of the PVN. Thus, it is likely that both direct steroid feedback and indirect input via neural circuits are involved in regulation of PVN CRH/AVP neurons.

One of the primary candidate brain structures implicated in HPA regulation is the hippocampal formation. This structure has been repeatedly shown to exhibit both a tonic inhibitory influence on HPA tone and to contribute to cessation of an initiated stress response $\mathrm{e}^{9,10,13,19,21,31,46}$. In addition, studies focusing on type-1 and type-2 glucocorticoid receptor binding and mRNA expression clearly demonstrate that the hippocampus possesses the highest levels of both receptor subtypes in irain, rendering this structure a likely target for integration of blood-borne glucocorticoid signals into a physiological response $2,11,27,28,32,36,42$.

The tonic inhibitory effect of the hippocampus on the HPA axis is likely to be integrated at the level of the PVN. We have previously demonstrated that both CRH and AVP mRNAs are markedly increased in the medial parvocellular PVN in response to hippocampal extirpation, implicating the hippocampal formation in tonic regulation of ACTH secretagogue gene expression $^{13}$. A hippocampal effect on ACTH secretagogue release was shown at the level of secretion by Sapolsky and colleagues, who demonstrated an effect of fimbria-fornix section on hypophysial portal CRH, AVP and oxytocin levels under both basal and stressed conditions $^{31)}$. Electrophysiological evidence further suggests an inhibitory interaction between the hippocampus and PVN cells identified as projecting to the median eminence, likely to reflect CRH-producing cells $^{29}$. What is not clear is how the hippocampus interacts with the PVN at an anatomical level. It is generally agreed that there is no direct connection between the hippocampus and the medial parvocellular PVN $^{34,39}$. However, potential circuits can be delineated which interconnect the hippocampus with PVN via one intervening synapse. One such circuit involves hippocampal connections with the lateral septum, bed nucleus of the stria terminalis and anterior hypothalamic structures via the fimbria-formix system ${ }^{20,38}$. These structures have been shown to project in turn to the medial parvocellular $\mathrm{PVN}^{34}$ or to the region immediately adjacent to the $\mathrm{PVN}^{3.23,34}$. A second potential circuit involves hippocampal-hypothalamic connections utilizing the medial corticohypothalamic tract, projecting from the anteroventral subiculum to the shell of the ventromedial nucleus, the arcuate nucleus, and the suprachiasmatic nucleus of the hypothalamus $^{20,37}$. In the present report, we attempt to functionally and anatomically identify the critical circuit for tonic hippocampal regulation of the HPA axis via selective lesion of forebrain fiber tract systems interconnecting the hippocampus and PVN.

\section{MATERIALS AND METHODS}

\section{Subjects and experimental protocols}

Subjects were male Sprague-Dawley rats, weighing $250-300 \mathrm{~g}$ at the time of surgery. All animals were housed on a $12: 12 \mathrm{~h}$ light:dark cycle (lights on $06.00 \mathrm{~h}$ ) in humidity- and temperature-controlled quarters.

Bilateral lesions of the fimbria-fornix were made using a microknife fashioned from the stylet of a 16 gauge spinal needle. The stylet was sharpened along the bottom and either side (resembling a chisel) to render it appropriate for smooth penetration into the brain and for mediolateral passage through fimbria-fornix fibers. The animals were placed in a stereotaxic apparatus (flat skull position) and the knife was lowered to the following coordinates, derived from the stereotaxic atlas of Paxinos and Watson ${ }^{25}: \mathrm{AP}-1.3 \mathrm{~mm}$ relative to bregma, DV $-5.0 \mathrm{~mm}$ and $\mathrm{ML}+0.5 \mathrm{~mm}$, and moved back and forth several times along the mediolateral plane some $2.5 \mathrm{~mm}$ using the stereotaxic micrometer control. The knife was then retracted and re-inserted in the other side of the brain and the identical process repeated. Control rats had the knife lowered only $2 \mathrm{~mm}$ on either side of midline, without mediolateral passage. Representations of the extent of fimbria-formix lesions are shown in Figs. 1 and 3.

For lesions of the medial corticohypothalamic tract (MCHT), knives were fashioned from is $\mathbf{2 3}$ gauge spinal needle. The stylet was threaded through the outer cannula, sharpened along the bottom and along two sides, and bent twice along an acute angle such that the knife shaft was parallel to the spinal needle cannula yet displaced by approximately $0.75 \mathrm{~mm}$ (see Fig. 2). The tip of the knife was positioned over Bregma, oriented anteriorly and dropped to the following coordinates: AP $-0.4, \mathrm{DV}-8.0, \mathrm{ML} 0.0$. Upon placement, the knife was then rotuted $90^{\circ}$ in either direction. The knife cut was designed to completely isolate the PVN from the MCHT, while sparing the post-commissural fornix passing nearby (see Figs. 2 and 3). Control rats had the knife lowered without rotation.

\section{Tissue harvesting and treatment}

Animals were killed by rapid decapitation 10 days following experimental or control lesions. All kills took place between 09.00 and $11.00 \mathrm{~h}$. corresponding to $3-5 \mathrm{~h}$ after lights-on. Brains were rapidly removed and frozen in isopentane cooled to $-45-50^{\circ} \mathrm{C}$ on dry ice. Blood was collected into heparinized tubes, spun at 1,500 $\times g$ for $10 \mathrm{~min}$, and plasma frozen at $-70^{\circ} \mathrm{C}$. for later analysis of ACTH and corticosterone.

Brains were cryostat-sectioned at $15 \mu \mathrm{m}$ and thaw-mounted onto polylysine-coated slides. All sections were stored al $-70^{\circ} \mathrm{C}$. until processing for in situ hybridization.

\section{In situ hybridization}

In situ hybridization was performed on sections sampled at regular $(75-90 \mu \mathrm{m})$ intervals through the PVN region according to a previously published protocol, with some minor modifications. Sections were removed from the $-70^{\circ} \mathrm{C}$ freezer, fixed in $4 \%$ paraformaldehyde for $30 \mathrm{~min}$ and deproteinated with $0.2 \mu \mathrm{g} / \mathrm{ml}$ proteinase $\mathrm{K}$ (is min at $37^{\circ} \mathrm{C}$ ). After deproteination slides were washed for $1 \mathrm{~min}$ in distilled $\mathrm{H}_{2} \mathrm{O}, 1 \mathrm{~min}$ in $0.1 \mathrm{M}$ triethe nolamine, and $10 \mathrm{mir}$ in $0.1 \mathrm{M}$ triethanolamine containing $0.25 \%$ acetic anlsydride. Sections we t $:$ then rinsed in distilled $\mathrm{H}_{2} \mathrm{O}$ and dehydrated through graded alcohols.

Antisense ${ }^{35} \mathrm{~S}$-iatleled cRNA probes to proAVP (Pst I fragment, subcloned in pGEM3, courtesy T.G. Sherman) and proCRH (BamHl 
fragment, subcloned in pGEM4, R.Thompson) cDNA clones were produced using standard in vitro transcription methodology. Plasmids containing subcloned $\mathrm{cDNAs}$ were linearized with appropriate restriction enzymes to yield probes of desired length and $C-G$ composition. The labeling reaction mixture contained $1 \mu \mathrm{g}$ linearized plasmid, $1 \times$ SP6 transcription buffer (BRL), $125 \mu \mathrm{Ci}$ [ ${ }^{35}$ S]UTP, 150 $\mu$ M NTPs-UTP, $12.5 \mathrm{mM}$ dithiothreitol, $20 \mathrm{U}$ RNAsin and $6 \mathrm{U}$ SP6 (AVP) or T7 (CRH) polymerase. Reactions were incubated for 90 $\min$ at $37^{\circ} \mathrm{C}$, and labeled probe separated from free nucleotide over a Sephadex G50-50 column. The proAVP probe was a 225 bp cRNA coding for the $\mathrm{C}$-terminal region of the proAVP molecule, which bears no significant homology with proOxytocin. The proCRH probe was a 770 bp cRNA derived from a rat CRH cDNA clone, including the peptide coding region (exon 2) of the rat CRH gene. ${ }^{35} \mathrm{~S}$-Labeled was added to the iranscription reaction in amounts calculated to yield specific activities estimated at $5.63 \times 10^{4} \mathrm{Ci} / \mathrm{mmol}$ probe and $1.73 \times 10^{5} \mathrm{Ci} / \mathrm{mmol}$ probe for proAVP and proCRH, respectively.

Probe was diluted in hybridization buffer (75\% formamide, $10 \%$ dextran sulfate, $3 \times$ SSC, $50 \mathrm{mM}$ sodium phosphate buffer, $\mathrm{pH} 7.4$ $1 \times$ Denhardt's, $0.1 \mathrm{mg} / \mathrm{ml}$ yeast tRNA and $0.1 \mathrm{mg} / \mathrm{ml}$ sheared salmon sperm DNA) to yield $1,000,000 \mathrm{dpm} / 30 \mu \mathrm{l}$ buffer. $30 \mu \mathrm{l}$ of the probe solution was applied to each slide, the slides coverslipped, and coverslips sealed with rubber cement. Slides were incubated in sealed plastic boxes containing moistened foam at $55^{\circ} \mathrm{C}$ overnight. Following incubation, the coverslips were removed, the slides rinsed in $2 \times$ SSC and immersed in fresh $2 \times$ SSC for $20 \mathrm{~min}$. The tissue was then incubated with RNAse $A(200 \mu \mathrm{g} / \mathrm{ml})$ at $37^{\circ} \mathrm{C}$ for $30 \mathrm{~min}$ to degrade any remaining single-stranded RNA. Sections were then washed successively in $2 \times, 1 \times$ and $0.2 \times$ SSC for 10 min each, followed by a $1 \mathrm{~h}$ wash in $0.2 \times$ SSC at the hybridization temperature. Sections were then dehydrated through alcohols, exposed to Kodak XAR X-ray film overnight, and subsequently emulsiondipped, along with slide-mounted $15 \mu \mathrm{m}$ brain-paste standards containing known amounts of ${ }^{35} \mathrm{~S}$-labeled L-methionine, in Kodak NTB2 nuclear emulsion. Emulsion-dipped sections and standards were exposed for 7-10 days (AVP) or 17-21 days (CRH); batch development was based on the signal strength and signal-to-noise ratio of test slides developed at regular intervals. Because of the large number of animals, tissue was processed in two (AVP) or three (CRH) runs, with all groups equally represented in each run.

Relative quantitation of in situ hybridization autoradiographs was conducted utilizing the NIH Image software package. Standards were prepared as described previously ${ }^{13}$ and sectioned at $15 \mu \mathrm{m}$, with adjacent sections reserved either for emulsion dipping or counting. Radioactivity of each standard was determined by counting standard sections adjacent to those used in the image analytic procedure in a Beckman liquid scintillation counter. Standard curves were derived by selecting the curve of best fit relating the optical density of digitized images of the ${ }^{35} \mathrm{~S}$-labeled brain paste standards (exposed along with the experimental sections) with the amount of radioactivity per unit area of standard. Emulsion-dipped sections were then digitized and subjected to analysis of optical density over the areas of interest in the images, those being the medial parvocellular and immediately adjacent posterior magnocellular divisions of the PVN. The region of PVN selected for both AVP and CRH analyses was the mid-portion of the medial parvoceilular PVN,

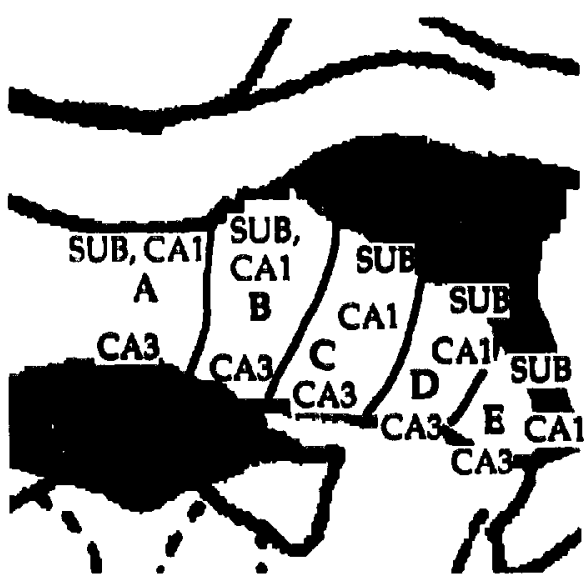

$$
\begin{aligned}
& A=\text { Anterior Dorsal HPC } \\
& B=\text { PosteriorDorsal HPC } \\
& C=\text { Posterior HPC } \\
& D=\text { Posterior Ventral HPC } \\
& E=\text { Anterior Ventral HPC }
\end{aligned}
$$
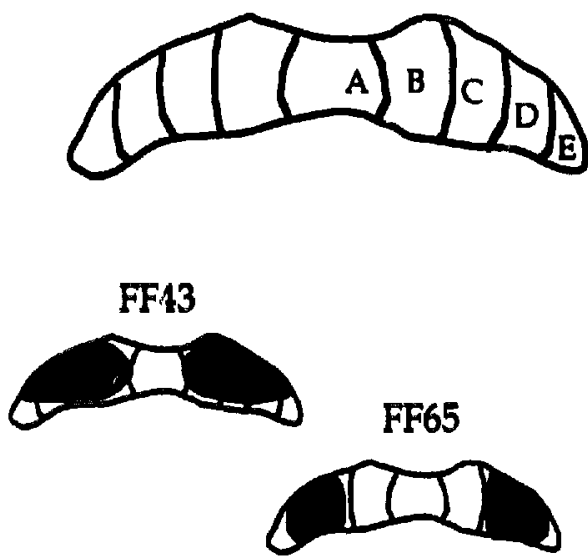

FF44

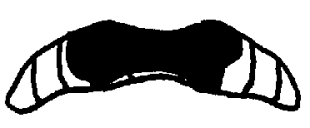

MFF
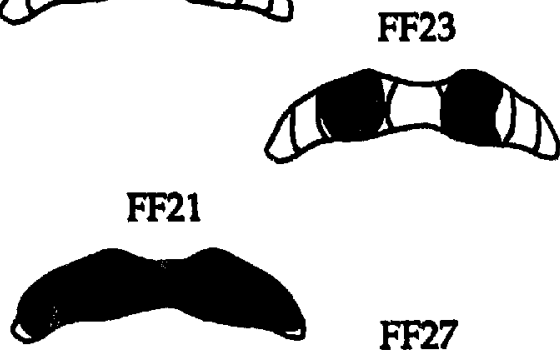

FF27

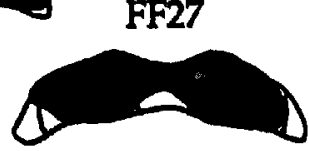

Fig. 1. Fimbria-fornix transections. For analysis of lesions, the fimbria-fornix (left panel) was subdivided according to the parcellation scheme of Meibach and Siegel ${ }^{211}$ into zones A-E, with A representing the most medial extent (cintaining efferents from the septal pole of the hippocampus) and $E$ the most lateral (containing effecsists from the temporal pole of the hippocampus). The distribution of efferents from various subfields of the hippocampal formation are depicted in their approximate locations (SUB, subiculum; CAl, cornu ammonis pyramidal cell layer 1; CA3, cornu ammonis pyramidal cell layer 3). Lesions are illustrated in the right panel, showing the most extensive (left) and least extensive (right) lesion included in the respective groups. LFF, lateral fimbria-fornix lesion; MFF, medial fimbria-fornix lesion; TFF, total

fimbria-fornix lesion. The left panel was a scanned and modified image from the atlas of Paxinos and Watson ${ }^{25}$, reproduced with permission. 
corresponding to $1,600-1,900 \mu \mathrm{m}$ posterior to bregma according to the coordinate scheme of Paxinos and Watson ${ }^{25}$. Areas of interest were defined on cytoarchitectonic criteria from adjacent Nissl-stained sections and by patterns of grain localization. Scattered magnocellular neurons in the medial parvocellular PVN interfere with accurate determination of the relative amount of parvocellular AVP mRNA localized in this region. We therefore endeavored to exclude magnocellular AVP neurons from our analysis of the parvocellular PVN on the basis of: (1) size and relative grain density and (2) known localization from neighboring Nissl-stained sections. Integrated optical density measures were then calculated by computing the product of the average optical density within the sample and the area sampled. All optical density measures utilized fell within the linear range of the computed standard curve.

\section{Hormone assays}

Plasma samples were extracted before assay with Sep-Pak C-18 cartridges. ACTH was assayed by radioimmunoassay using a rabbit ACTH antibody directed against ACTH (11-24). Details of this assay have been described previously ${ }^{48}$. Plasma CORT was also determined by RIA, using a rabbit antibody directed against corticosterone (conjugated with bovine serum albumin) (B3A, courtesy of M. Morano and E. Estivariz). This antiserum cross-reacts $2 \%$ with cortisol and deoxycorticosterone and less than $0.3 \%$ with progesterone, estradiol, testosterone, and aldosterone. Extracted and lyophilized samples were resuspended in $50 \mathrm{mM}$ sodium phosphate buffer (pH 7.5) in the presence of $2.5 \%$ bovine serum albumin. The corticosterone antiserum was used at a final concentration of $1: 4,000$. $\left[{ }^{3} \mathrm{H}\right]$ Corticosterone (Amersham, Arlington Heights, IL) was used as a trace. Bound and free steroids were separated via centrifugation
$(3,000 \times g)$ in the presence of a $1 \% / 0.1 \%$ charcoal/dextran mixture. Corticosterone concentrations of $0.5 \mu \mathrm{g} / \mathrm{dl}$ were reliably detected using this assay system (intra-assay coefficient of variation = $2 \%$, inter-assay coefficient of variation $=3 \%$ ).

\section{Data analysis}

All data were analyzed by one-way ANOVA, followed by Duncan's Multiple Range post-hoc analysis to differentiate among individual means (SuperANOVA software, Abacus Concepts, Berkeley, CA). All ANOVAs used the mean integrated optical density, ACTH and CORT values obtained for each individual animal, and were grouped according to surgery (sham fimbria-fornix (SH-FF) and sham MCHT (SH-MCHT)) or histologically verified lesions (LFF, TFF, MFF, MCHT). Note that due to tissue availability, AVP analyses were only performed on 2 of 3 runs.

\section{RESULTS}

Representative lesions of the FF and MCHT are presented in Figs. 1-3. Note that the total FF (TFF), lateral FF (LFF) and medial FF (MFF) groups were defined post-hoc on the basis of the histological appearance of the lesion sites in Nissl-stained sections. Criteria for successful lesions were as follows: LFF, destruction of the lateral extent of the fimbria-fornix (Fig. 1B, zones C-D, with subtotal damage of zone $\mathrm{E}$;
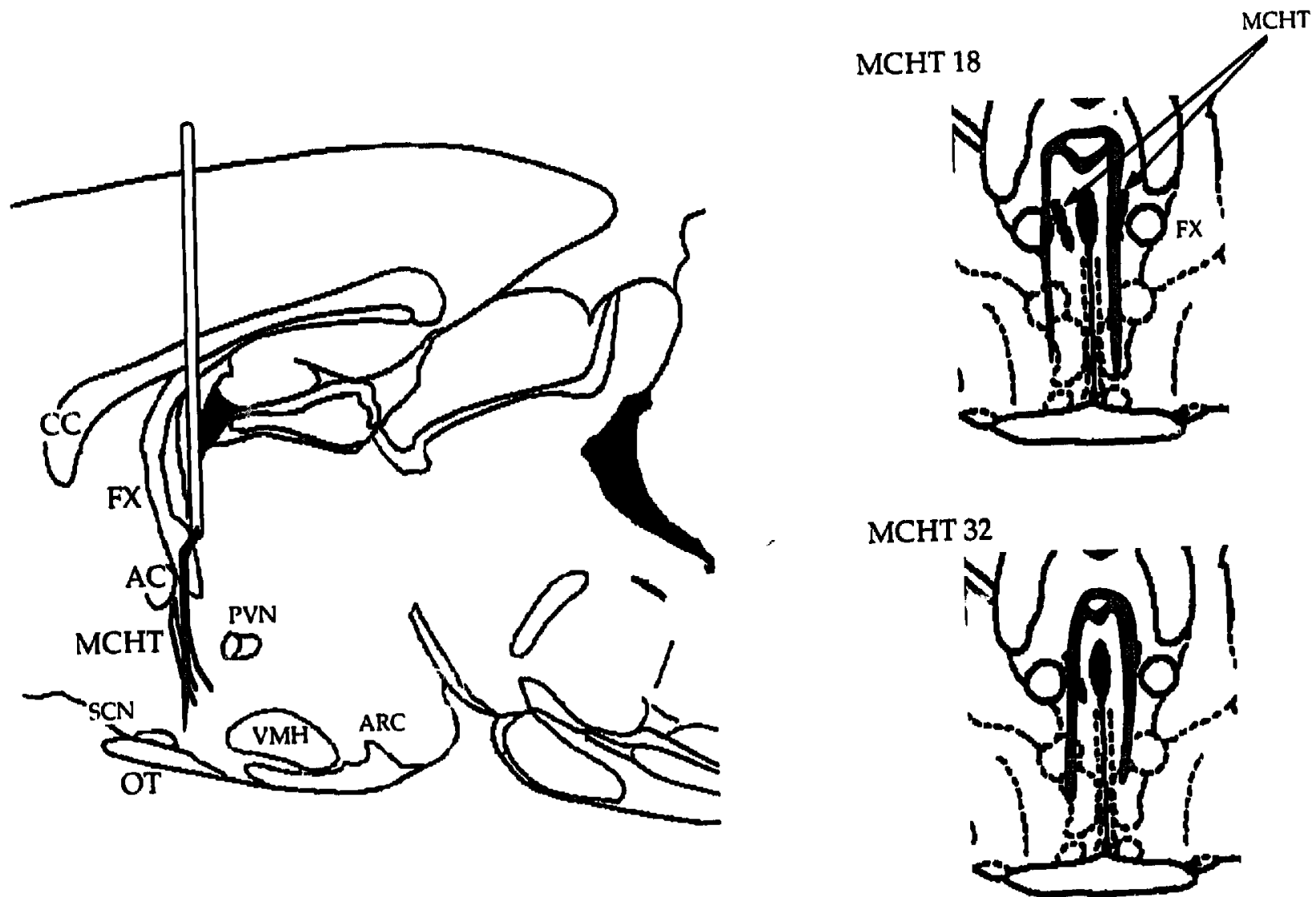

Fig. 2. Medial corticohypothalamic tract (MCHT) iransections. The MCHT was sectioned at approximately the level depicted in the left panel, with the knife blade positioned between the origin of the MCHT from the fornix and fascicles descending into the hypothalamus. The knife was designed to be interposed between the two descending columns of the fornix (see right panel) to obviate damage to information travelling in this fiber system, and was positioned to clearly avoid damage to the paraventricular nucleus (PVN). The right panel shows the largest (top) and most circumscribed (bottom) MCHT cuts utilized in our data analysis. Both panels are modified images from the atlas of Paxinos and Watson ${ }^{25}$, reproduced with permission. 
Fig. 3); MFF, destruction of the medial region of the fimbria-fornix (Fig. 1B, zones A-C; Fig. 3); TFF, destruction of the majority of the fimbria-fornix (Fig $1 B$, zones $A-D$, with some sparing of the lateral tip of the fornix (zone E) generally present; Fig. 3); and MCHT (Figs. 2 and 3), interposition of the knife scar between the descending columns of the fornix and the third ventricle in such a manner that descending fascicles of the MCHT were interrupted (Fig. 2) (with no accompanying damage to either the fornix or PVN). Note that the TFF lesion resulted in more extensive damage to overlying cortex than the MFF or LFF groups (e.g. see Fig. 3).

Analysis of CRH and AVP mRNA expression following the respective lesions is presented in Figs. 4-6. Determinations were made on 2-4 (4-8 PVN) sections through the mid-portion of the PVN of each animal $(1,600-1,900 \mu \mathrm{m}$ posterior to bregma). As can be ap-

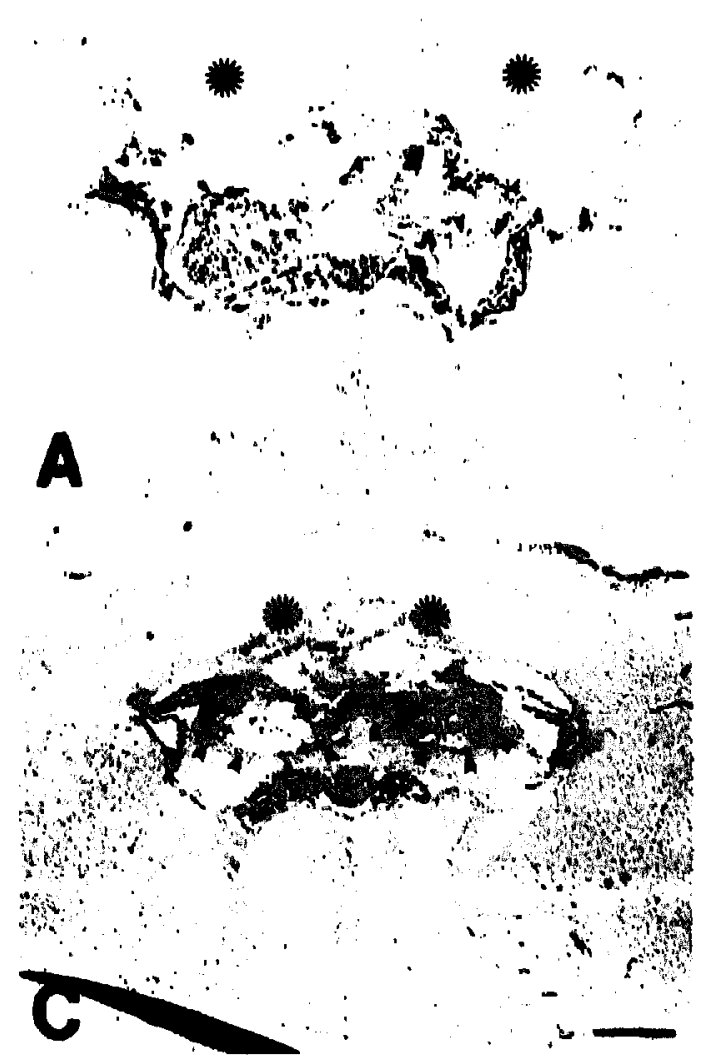

preciated in Fig. 4, an up-regulation of CRH mRNA can be observed in the medial parvocellular PVN of rats receiving either TFF or LFF lesions. In contrast, no obvious changes were observed in the MFF and MCHT groups relative to sham-operated controls. Densitometric data reiterates the qualitative microscopic observations, demonstrating a significant effect of treatment on CRH mRNA levels (Fig. 5) $\left(F_{5,49}=\right.$ 3.74, $P<0.01)$ upon one-way ANOVA. Post-hoc analysis using Duncan's Multiple Range test revealed significant differences between both the TFF and LFF groups and sham-operated controls $(P<0.05)$.

Changes in AVP mRNA can be seen as an increase in hybridization density over the medial parvocellular PVN following disruption of the fimbria-fornix, allowing visualization in some sections of clear parvocellular AVP neurons (Fig. 6). Densitometric examination (Fig. 5) revealed a significant change in medial parvocellular

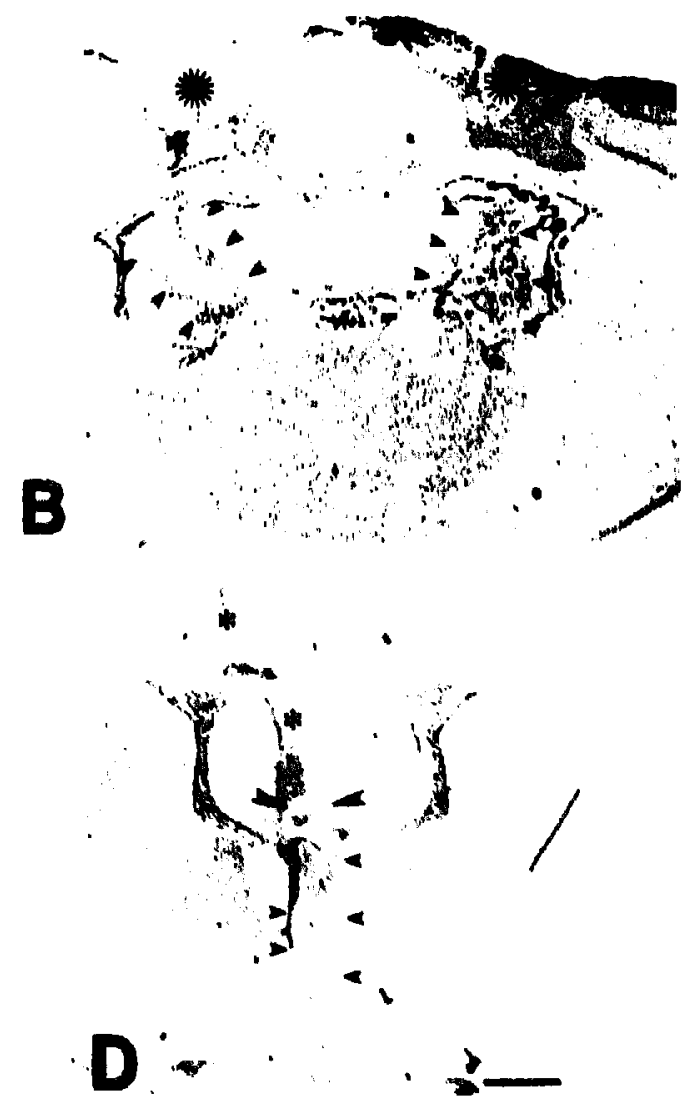

Fig. 3. Histology of representative total fimbria-fornix (TFF)(FF57) (A), lateral fimbria-fornix (LFF) (FF65) (B), medial fimbria-fornix (MFF) (FF44) (C) and medial corticohypothalamic tract (MCHT) (MCHT18) (D) lesions, stained for Nissl substance with Cresyl violet. A: TFF lesions typical compromised the vast majority of the fimbrin-fornix at the level depicted, with some sparing of the ventrolateral tip (sec arrows). Cortical damage was sustained in the area overlying the knife cut (asterisks). B: LFF lesions were confined to the lateral region of the fimbria-fornix. corresponding roughly to zones $C$ and $D$ in Fig. I. The area of lesion is delimited by the arrows. Note thut the damage to overlying cortex is more limited compared with that seen in TFF lesions. C: MFF lesions typically encompassed the medial half of the fimbria-fornix at this level (denoted by arrows); substantial sparing of zones $C$ and D (Fig. 1) are seen in these lesions. The extent of damage to overlying cortex (not fully appreciated in this section) was similar to that seen for LFF lesions. D: MCHT lesions involved bilateral interposition of a microknife blade between the fornix and the path of descending fibers of the MCHT. The knife scars are denoted by small arrows, and the mechanical damage caused by positioning of the knife is demonstrated by the larger arrows. The asterisks illustrate the approach taken to position the knife blade. Note that the knife scars are in a position appropriate to bilaterally bisect the MCHT (compare with Fig. 2), without causing significant damage to the nearby post-commissural fornix. Bar $=1 \mathrm{~mm}$. 

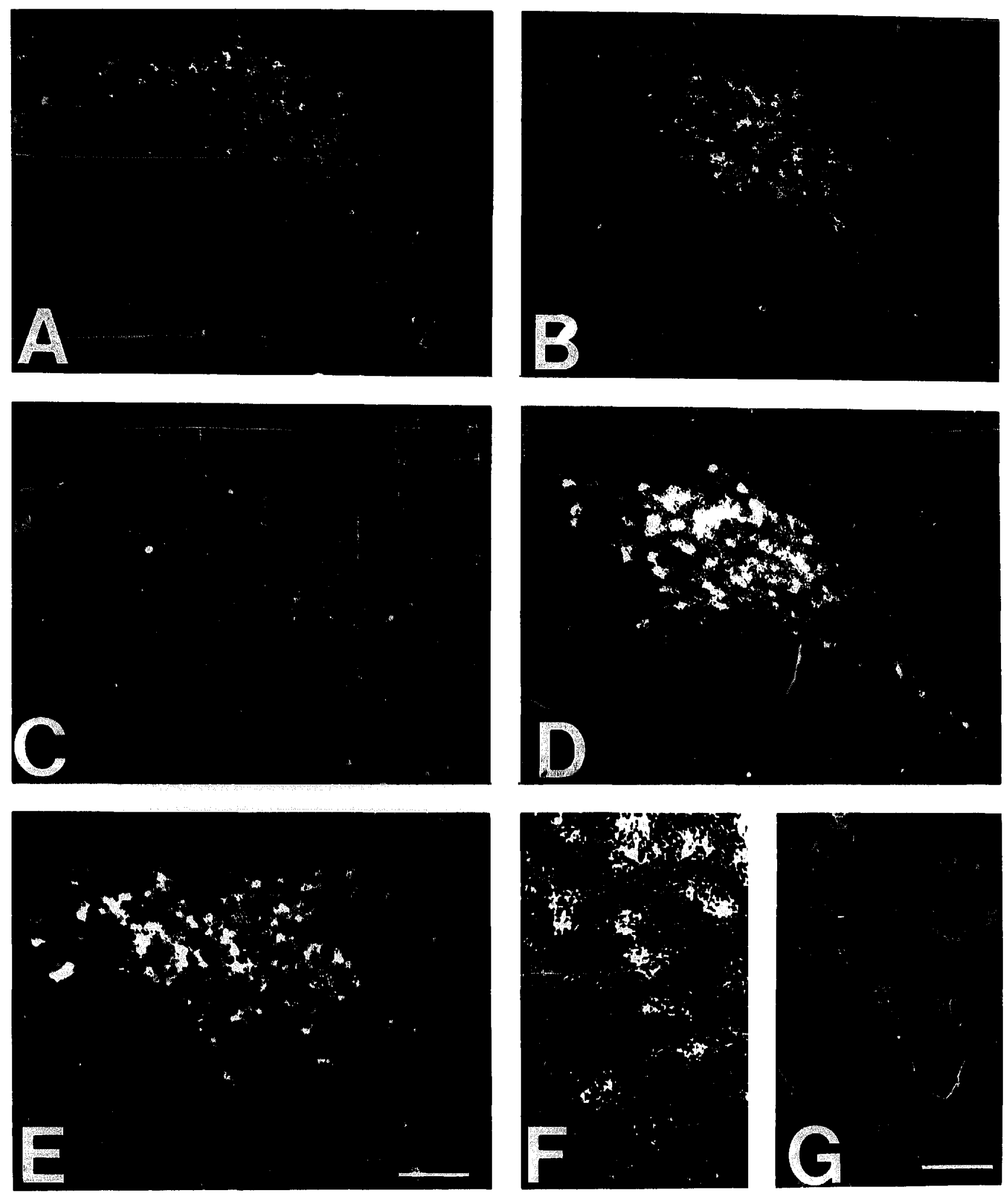

Fig. 4. Examples of CRH mRNA in the medial parvocellular division of the paraventricular nucleus of rats receiving sham lesions (A), medial fimbria-fornix transections (B), medial corticohypothalamic tract lesions (C), lateral fimbria-fornix transections (D), and total fimbria-fornix transections (E). These sections were selected to depict approximate percentage of control valuts at their respective rostrocaudal level of the nucleus (integrated OD value of $\mathrm{A}(\mathrm{SHAM})=121 \%$ of mean control (SHAM) values at this anatomical level, $\mathrm{B}(\mathrm{MFF})=91 \%, \mathrm{C}(\mathrm{MCHT})=94 \%$, $\mathrm{D}(\mathrm{LFF})=198 \%, \mathrm{E}(\mathrm{TFF})=258 \%$ ). Cells depicted in $\mathrm{F}$ and $\mathrm{G}$ represent qualitative differences in grain density/cell seen in TFF (F) vs. SHAM (G) animals. Bar $=100 \mu \mathrm{m}$. 


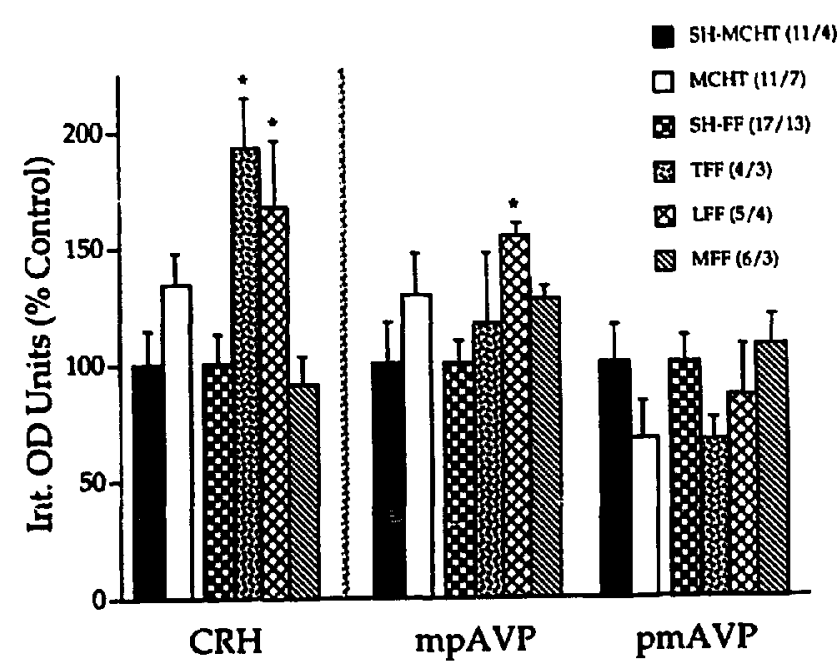

Fig. 5. Semi-quantitative analysis of CRII and AVP mRNA expression in the paraventricular nucleus following sham medial corticohypothalamic tract lesion (SH-MCHT), medial corticohypothalamic tract lesions (MCHT), sham fimbria-fornix lesion (SH-FF), total fimbria-fornix lesions (TFF), lateral fimbria-fornix lesions (LFF), or medial fimbria-fornix lesions (MFF). The MCHT lesion data and the TFF, LFF and MFF data are expressed as percentages of the SH-MCHT and SH-FF control groups, respectively; please note that these two control groups did not differ from one another. In response to TFF or LFF, CRH mRNA levels in the medial parvocellular PVN are significantly increased over sham-operated controls ( $P<0.05$ for both lesions, Duncan's Multiple Range test, following significant one-way ANOVA). AVP mRNA levels were increased in the medial parvocellular (mp) PVN of LFF rats $(P<0.05$, Duncan's Multiple Range test, following significant one-way ANOVA). There was no effect of lesion on posterior magnocellular (pm) PVN AVP mRNA content. Numbers in parentheses indieate the number of animals / group for the CRH (first number) and AVP (second number) anulyses.

PVN AVP mRNA levels $\left(F_{5,25}=2.62, P<0.05\right)$; this effect was primarily carried by the LFF group, as only the LFF lesion was statistically differentiable from sham-operated controls by post-hoc analysis $(P<0.05$, Duncan's Multiple Range test). Magnocellular AVP mRNA levels were not altered by any surgical treatment.

Radioimmunoassay of trunk blood samples from the respective groups are presented in Table I. There was a significant effect of group on plasma ACTH by one-way ANOVA $\left(F_{5.52}=2.34, P=0.05\right)$; upon posthoc analysis, only the LFF group was differentiable from control animals (Duncan's Multiple Range test $(P<0.05))$. There was no significant effect of treatment on plasma corticosterone (CORT) levels (overall ANOVA: $F_{5,52}=1.15, P=0.35$ ).

\section{DISCUSSION}

This study demonstrates that lesions of the fimbria-fornix system can reliably elicit increases in basal CRH and AVP mRNA levels in medial parvocel- lular PVN neurons known to control HPA axis function. Notably, this effect appears to be quite localized within the fornix system; lesions of the lateral extent of the fornix (approximately corresponding to zones C and $D$ of Meibach and Siegel ${ }^{20}$ : see Fig. 1) were most efficacious in producing basal up-regulation of both CRH and AVP mRNA and increases in plasma ACTH levels, whereas medial lesions were unable to significantly up-regulate ACTH secretagogue mRNAs. These data support the hypothesis that information travelling in zones $\mathrm{C}$ and $\mathrm{D}$ of the fornix, emanating from CA1 and ventral subicular pyramidal cells of the ventral hippocampus, are likely to be the principle hippocampal regulators of basal HPA tone.

Lesions of the MCHT were unable to affect $\mathrm{CRH}$ and AVP mRNA production and HPA axis secretions. Interestingly, fibers of the MCHT typically travel in zones $D$ and $E$ of the fornix system, many of which should be spared by the LFF and TFF lesions. Taken together, these data suggest that direct projections of hippocampal neurons to the region of the mediobasal hypothalamus are unlikely to be primary modulators of basal ACTH secretagogue production.

The parcellation of hippocampal-HPA interactions to the lateral extent of the fornix system agrees with data obtained by Fischette et al. ${ }^{10}$, who demonstrated a significant disruption of basal CORT secretion following lateral but not medial fimbria-fornix transections. In addition, ventral hippocampal cortisol implants appear to disrupt daily CORT secretions ${ }^{35}$, suggesting that the region giving rise to lateral fornical fibers may be implicated in steroid-mediated HPA control. Interestingly, both of the above effects were manifested as a disruption of circadian CORT rhythmicity. It is known

\section{TABLE I}

Plasma ACTH and corticasteronc levels following forcbrain filher tract lesion

SH-MCHT, sham-medial corticohypothalamic tract; MCHT, medial corticolyypothalamic tracl; SH-FF, sham fimbria-fornix; TFF, total fimbria-fornix; LFF, lateral fimbria-fornix; MFF, medial fimbriafornix.

\begin{tabular}{lll}
\hline Lesion group & Plasma ACTH & $\begin{array}{l}\text { Plasma CORT } \\
(\mathrm{fmol} / \mathrm{ml})\end{array}$ \\
\hline SH-MCHT & $24.0 \pm 4.9(9) "$ & $3.18 \pm 1.59(10)$ \\
MCHT & $28.3 \pm 13.5(11)$ & $1.65 \pm 0.94(11)$ \\
SH.FF & $33.6 \pm 6.0(22)$ & $3.41 \pm 1.05(20)$ \\
TFF & $57.2 \pm 14.4(6)$ & $3.00 \pm 0.66(5)$ \\
LFF & $76.8 \pm 21.7(5)^{\mathrm{h}}$ & $5.07 \pm 2.83(6)$ \\
MFF & $54.6 \pm 21.5(5)$ & $6.87 \pm 2.41(6)$ \\
\hline
\end{tabular}

Mean \pm S.E.M. Numbers in parenthesis reflect the number of animals/groups.

b Significantly different from the SH-FF group by Duncan's Multiple Range Test, following significant one-way ANOVA. 

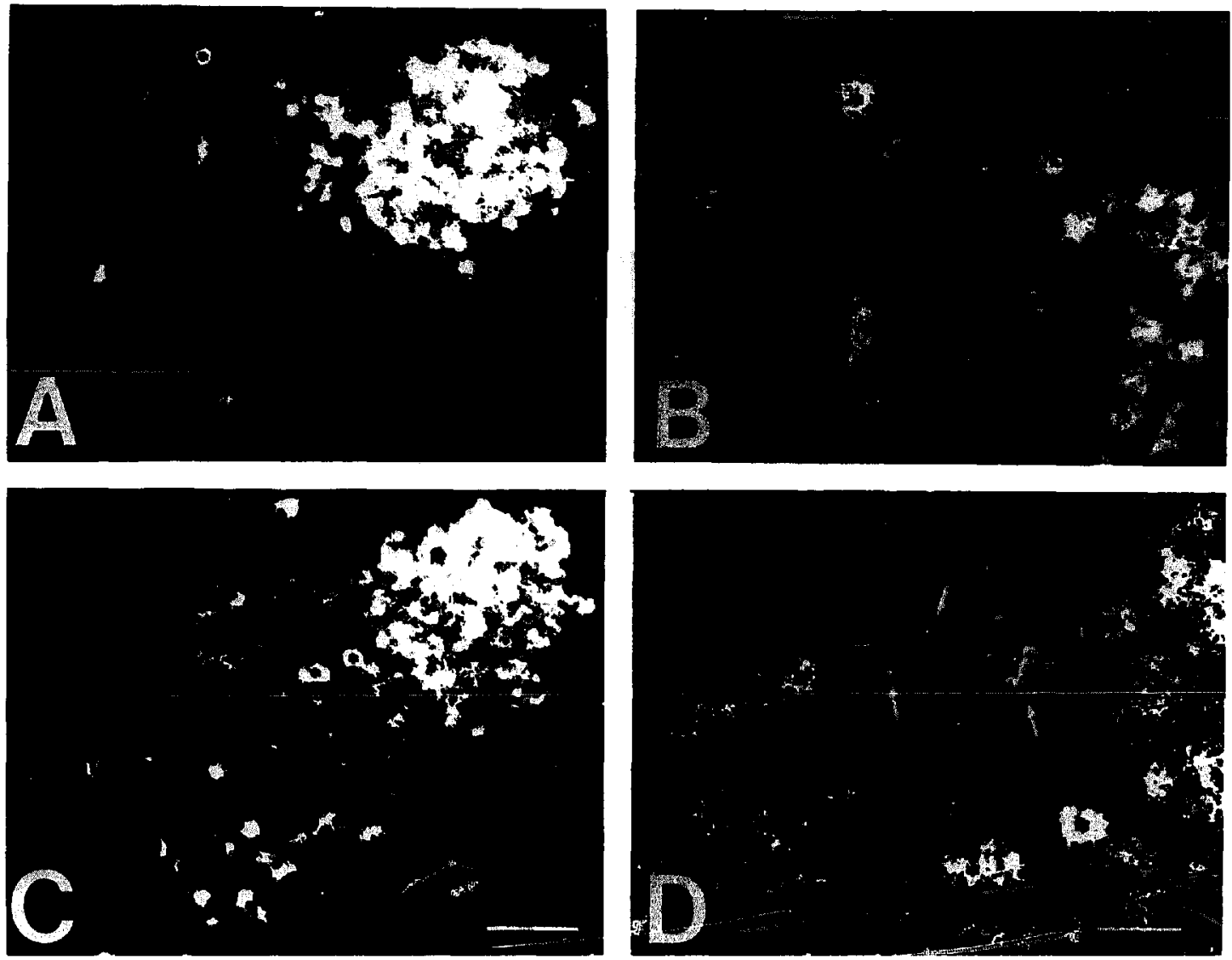

Fig. 6. Examples of AVP mRNA distribution in the medial parvocellular division of the paraventricular nucleus of rats receiving sham lesion $(A, B)$ or lateral fimbria-fornix transection (LFF) (C,D). Note the presence of positive hybridization in the medial parvocellular zone in the LFF animal (C), many of which can be localized to the small, lightly hybridized neuronal profiles seen in panel D (arrows). No such hybridization signal is seen in the parvocellular zone of SHAM animals (A), or in identifiable parvocellular elements (B). Asterisks depict the same neurons in panels $A$ and $B$ and panels $C$ and $D$; these neurons are representative of scattered magnocellular neurons commonly seen in the medial parvocellular PVN. Bars $=100 \mu \mathrm{m}(\mathrm{A}, \mathrm{C})$ and $40 \mu \mathrm{m}(\mathrm{B}, \mathrm{D})$.

that the HPA axis shows marked circadian rhythms at multiple levels, including CORT, ACTH and CRH secretion $^{6,22,24,40}$ and CRH mRNA production ${ }^{18,43}$. In combination with the present data, these studies suggest the possibility that information carried from the ventral hippocampus via the lateral fornix may be involved in steroid-mediated modulation of HPA rhythms. However, comparison of the previous circadian studies of CRH mRNA regulation with hippocampus--fornix lesion results does yield some interesting discrepancies to keep in mind. First, the daily excursion of CRH mRNA content in the PVN is considerably less than changes observed following hippocampal-fornix lesions ${ }^{18,43}$. Second, under lesion conditions AVP mRNA is significantly increased in parvocellular PVN neurons, whereas such changes are not evident across the circadian cycle (Herman, McEwen, Chao and Watson, unpublished observations). Such data seems to argue that the lesion condition is a more potent activator of the CRH/AVP neuron than circadian drive. While one could hypothesize that total removal of circadian inhibitory events may transcend those events occuring across the daily cycle, the possibility that ventral hippocampus damage, /disconnection drives CRH/AVP mRNA expression in the parvocellular PVN without regard to time of day merits further attention as well.

The plasma hormone data present an interesting pattern. In the LFF group, ACTH secretion appears to be increased without an accompanying change in CORT levels. One explanation for this phenomenon is that slight elevations of ACTH in the LFF group may reflect the beginnings of a stress response to the events associated with killing. Our animals are killed within 1 min of retrieval from their home cages; however, the commotion associated with vivarium room noise, removal of other rats from neighboring, etc, may be sufficient to initiate ACTH secretion in animals (e.g. LFF-damaged rats) whose HPA axis has been previously sensitized to stress. Up-regulation of CRH and AVP mRNAs in LFF rats may then be the consequence of an increase in overall sensitivity of the axis 
driven by hippocampal disconnection, and prescribes a preparatory (i.e. encoding predispositions to synthesis/ secrete) rather than permissive (i.e. encoding tonic inhibition of biosynthesis/secretion) interaction of this structure with the HPA axis.

Differential effects on the HPA axis were observed between groups with total fornix lesions and lesions confined to the lateral fornix. It appears that LFF lesion results in increased AVP mRNA, CRH mRNA and ACTH levels, while only CRH mRNA changes are seen upon TFF lesions. This pattern raises the possibility that different classes of information relevant to HPA axis regulation are encoded in different regions of the hippocampus or different hippocampal subfields. There is precedent for such effects in the literature, in that stimulation of CA1 appears excitatory to corticosteroid secretion in anesthetized preparations, whereas CA3 or dentate gyrus stimulation appears primarily inhibitory ${ }^{8}$. In addition, lesion of the dentate gyrus with intraventricular colchicine decreases rather than increases CRH mRNA in the PVN ${ }^{4}$. By this logic, one would suspect that the inhibitory actions of ventral hippocampal structures on the PVN (seen in the LFF condition) may be tempered in TFF animals by removal of other classes of outflow emanating from functionally distinct hippocampal regions.

The presence of increased AVP mRNA and clevated ACTH in the LFF group may be connected. It is known that AVP and CRH act synergistically at the corticotroph to release $A C T H^{12}$, and that the extent of co-localization of AVP and CRH in neurosecretory granules in the external lamina of the median eminence increases dramatically with stimulation (chronic stress or adrenalectomy) ${ }^{44,45}$. Interestingly, in both the case of TFF and LFF CRH mRNA was increased, yet ACTH secretion was only affected under conditions where AVP mRNA was increased as well (LFF). These results raise the possibility that the ACTH change may be connected to increased AVP synthesis, with putatively increased levels of AVP at the median eminence capable of promoting greater corticotroph release of ACTH per stimulatory episode. This hypothesis remains to be definitively addressed.

It should be noted that the TFF lesion resulted in more extensive cortical damage than either the LFF or MFF transections. However, the fact that the effects of LFF on several measures of HPA activity were as great as or greater than those of the TFF group precludes a role for differential cortical destruction in the present experiments.

It is clear from this study that levels of CRH and AVP mRNAs are subject to regulation by hippocampal structures. It remains to be determined which sub-hip- pocampal structures are capable of directing hippocampal influence to the PVN itself. Certainly, dorsal hippocampal projections travelling in fornix zones A and $B$ (compromised by MFF lesions) are not likely to be important HPA-active elements. These efferents distribute in a topographic fashion to the dorsal and latera! septum ${ }^{20,38,47}$. In fact, in general the septum is a poor candidate for a hippocampus-PVN relay, as anterograde tracing data suggest that descending septal fibers largely avoid the PVN, skirting the outer boundaries of the nucleus ${ }^{23,34}$. In addition, the temperoventral hippocampal projections to the mediobasal hypothalamus are ruled out by the ineffectiveness of the MCHT lesion to alter either CRH and AVP mRNA levels or HPA axis secretions. What remains is a relatively restricted source of potential interconnections between the ventral hippocampus-subiculum and selected structures in the tel- and di-encephalon. Previous tract-tracing data strongly indicate that the best potential sources for such interaction lie in the bed nucleus of the stria terminalis, preoptic area, zona incerta and anterior hypothalamus. All of these regions receive afferents from the ventral subiculum, and in turn project to the medial parvocellular $\mathrm{PVN}^{34.38}$. Indeed, fibers projecting from hippocampus to these regions can be clearly localized to that region of the fornix (zone D) compromised by the LFF lesion ${ }^{5,21}$. Subsequent functional-anatomical studies will be necessary to differentiate among these probable relay candidates.

While suggesting an involvement of ventral hippocampal corticosteroid receptors in regulation of PVN CRH/AVP mRNA expression, the present experiments do not directly address which receptor type, if any, is involved in these processes. However, consideration of literature reports and recent experiments performed in several laboratories would seem to point to the type-1 receptor as a potential vehicle for ventral hippocampal regulation of the HPA axis. Slusher's early study utilizing crystalline cortisol implants certainly suggests a steroid-mediated ventral hippocampal influence on circadian CORT rhythmicity, although it does not implicate either receptor convincingly ${ }^{35}$. On the other hand, Ratka et al. describe an increase in AM CORT levels following intracerebroventricular injection of the type-1 antagonist RU28318, leading to their ascribing a role for this receptor in circadian HPA cycles ${ }^{26}$. Unfortunately, the locus of action of the RU28318 in this study is impossible to determine. Similarly, Dallman and colleagues, based on the rankorder potency of CORT, dexamethasone and aldosterone on inhibition of adrenalectomy-induced ACTH up-regulation, attribute regulation of circadian $\mathrm{ACTH}$ 
secretion to (presumably extrahypothalamic) type-1 receptors ${ }^{7}$. Our efforts to assess type-1 inhibition of the CRH/AVP parvocellular neurons indicate that chronic, systemic blockade of the type-1 corticosteroid receptor is able to reliably increase both $\mathrm{CRH}$ and AVP mRNA content in the morning, without affecting evening levels ${ }^{14}$. Although derived from systemic administration, the fact that RU28318 treatment elicits effects similar in scope and magnitude to LFF lesions in animals killed at corresponding points in the day is suggestive of a circadian interaction between the type-1 receptor and ventral hippocampus in regulation of the CRH/AVP neuron.

The present studies provide evidence for specific, tonic inhibitory interactions between the ventral hippocampus-subiculum and PVN cells responsible for HPA activation, occurring via intervening structures in the ventral forebrain-hypothalamus. These studies localize the effects seen following whole hippocampal removal ${ }^{13}$ to this specific sub-region of the hippocampus, and point to a contribution of the ventral hippocampus in regulation of basal HPA tone. Subsequent studies are necessary to determine whether the ventral hippocampal influence on medial parvocellular PVN neurons is related to circadian mechanisms and/or steroid receptors.

Acknowledgements. The authors would like to thank Amanda Frisch. Anthony Savinu, James Stewart, and Kathy deYoung for invaluable technical ussistance, Dr. Seung Kwak for his critical reading of this munuscript, and Dr. Thomas Sherman and Dr. Robert Thompson for their generous gifts of the AVP and CRH cDNA clones, respectively. This work was supported by NS08267 (J.P.H.), DK07245 (W.E.C.). DA02265 (S.J.W., H.A.). MH422SI (S.J.W., H.A.).

\section{REFERENCES}

1 Antoni, F.A., Hypothalamic control of adrenocorticotropi,ı secretion: advances since the discovery of 41-residue corticotropin-releasing factor, Endocrine Rev., 7 (1986) 351-378.

2 Arriza, J.L., Simerly, R.B., Swanson, L.W. and Evans, R.M. Neuronal mineralocorticoid receptor as a mediator of glucocorticoid response, Neuron, 1 (1988) 887-900.

3 Berk, M.L. and Finkelstein, J.A., Afferent projections to the preoptic and hypothalamic regions in the rat brain, Neuroscience, 6 (1981) 1601-1624.

4 Brady, L.S., Lynn, A.B., Whitfield, H.J. and Herkenham, M, Intrahippocampal colchicine alters hypothalamic corticotropin-releasing hormone and hippocampal steroid receptor mRNA in rat brain. Neuroendocrinology, 5.5 (1991) 121-133.

5 Cullinan, W.E., Herman, J.P. and Watson, S.J., Morphological evidence for hippocampal interaction with the hypothalamic paraventricular nucleus, Soc. Neurosci. Abstr., 17 (1991) 990.

6 Dallman, M.F., Akana, S.F., Cascio, C.S., Darlington, D.N., Jacobson, L. and Levin, N., Regulation of ACTH secretion: variations on a theme of B, Recent Prog. Horm. Res., 43 (1987) 113-173.

7 Dallman, M.F., Levin, N., Cascio, C.S., Akana, S.F., Jacobson, L. and Kuhn, R.W., Pharmacological evidence that the inhibition of diurnal adrenocorticotropin secretion by corticosteroids is medi- ated via type-I corticosterone-preferring receptors, Endocrinology, 124 (1989) 2844-2850.

8 Dunn, J.D. and Orr, S.E., Differential plasma corticosterone responses to hippocampal stimulation, Exp. Brain Res., 54 (1984) 1-6.

9 Fendler, K., Karmos, G. and Telegdy, G., The effect of hippocampal lesion on pituitary-adrenal function, Acta Physiol. (Budapest), 20 (1961) 283-297.

10 Fischette, C.T., Komisaruk, B.R., Edinger, H.M., Feder, H.H. and Siegel, A., Differential fornix ablations and the circadian rhythmicity of adrenal corticosteroid secretion, Brain Res., 195 (1980) 373-387.

11 Fuxe, K., Wikstrom, A.C., Okret, S., Agnati, L.F., Harfstrand, A. Yu, Z.Y., Granholm, L., Zoli, M., Vale, W. and Gustafsson, J.A., Mapping of glucocorticoid receptor immunoreactive neurons in the rat tel- and diencephalon using a monoclonal antibody against rat liver glucocorticoid receptor, Endocrinology, 117 (1985) 18031812.

12 Gillies, G.E., Linton, E.A. and Lowry, P.J., Corticotropin-releasing activity of the new CRF is potentiated several times by vasupressin, Nature, 299 (1982) 355-357.

13 Herman, J.P., Schäfer, M.K.-H., Young, E.A., Thompson, R., Douglass, J., Akil, H. and Watson, S.J., Evidence for hippocampal regulation of neuroendocrine neurons of the hypothalamopituitary-adrenocortical axis, J. Neurosci, 9 (1989) 3072-3082.

14 Herman, J.P., Watson, S.J. and Spencer, R., Treatment with the type-I glucocorticoid receptor antagonist, RU28318, alters circadian patterns of CRH mRNA expression in the hypothalamic paraventricular nucleus, Program of the Endocrine Soc. 72 nd Annual Meeting, 1990, Abstract, p. 287.

15 Herman, J.P., Wiegand, S.J. and Watson, S.J., Regulation of basal corticotropin-releasing hormone and arginine vasopressin messenger ribonucleic acid expression in the paraventricular nucleus: effects of selective hypothalamic deafferentations, $E n$ docrinology, 127 (1990) 2408-2417.

16 Keller-Wood, M. and Dallman, M.F., Corticosteroid inhibition of ACTH secretion, Endocrine Reu., 5 (1984) 1-24.

17 Kovacs, K.J., Kiss, J.Z. and Makara, G.M., Glucocorticoid implants around the hypothalamic paraventricular nucleus prevent the increase of corticotropin-releasing factor and arginine vasopressin caused by adrenalectomy, Neuroendocrinology, 44 (1986) 229-234.

18 Kwak, S.K, Young, E.A., Morano, M.I., Watson, S.J, and Akil, H., Diurnal corticotropin-releasing hormone mRNA variation in the hypothalamus exhibits : rhythm distinct from that of plasma corticosterone, Neuroendocrinology. 55 (1991) 74-83.

19 Magarinos, A.M., Somoza, G. and DeNicola, A., Glucocorticoid negative feedback and glucocorticoid receptors after hippocampectomy in rats, Horm. Metab. Res., 19 (1987) 105-109.

20 Meibach, R.C. and Siegel, A., Efferent connections of the hippocampal formation in the rat, Brain Res, 124 (1977) 197-224.

21 Moberg, G.P., S. !pagnini, U., Groot, J.D. and Ganong, W.F., Effect of sectioning the fornix on diurnal fluctuation in plasma corticosterone levels in the rats, Neuroendocrinology, 7 (1971) 11-15.

22 Moldow, R.L. and Fischman, A.J., Physiological changes in rat hypothalamic CRF: circadian, stress and steroid supression, Peptides, 3 (1982) 837-840.

23 Oldfield, B.J. and Silverman, A.-J,, A light microscopic HRP study of limbic projections to the vasopressin-containing nuclear groups of the hypothalamus, Brain Res. Bull., 14 (1985) 143-157.

24 Owens, M.J., Bartolome, J., Schanberg, 3.M. and Nemeroff, C.B. Corticotropin-releasing factor concentrations exhibit an apparent diurnal rhythm in hypothalamic and extrahypothalamic brain regions: differential sensitivity to corticosterone, Neuroendocrinology, 52 (1990) 626-631.

25 Paxinos, G. and Watson, C., The Rat Brain in Stereotaxic Coordinates, Academic Press, Orlando, 1986.

26 Ratka, A., Sutanto, W., Bloemers, M. and deKloet, E.R., On the role of brain mineralocorticoid (type I) and glucocorticoid (type 11) receptors in neuroendocrine regulation. Neuroendocrinology, 50 (1989) $117-123$. 
27 Reul, J.M. and deKJoet, E.R., Two receptor systems for corticosterone in rat brain: microdistribution and differential occupation, Endocrinology. 11 ? (1985) 2505-2511.

28 Reul, J.M. and deKloet, E.R., Anatomical resolution of two types of corticosterone receptor sites in rat brain with in vitro autoradiography and computerized image analysis, $J$. Steroid Biochem., 24 (198b) 269-272.

29 Saphier, D. and Feldman, S., Effects of septal and hippocampal stimuli on paraventricular nucleus neurons, Neuroscience, 20 (1987) 749-755.

30 Sapolsky, R.M., Armanini, M.P., Sutton, S.W. and Plotsky, P.M., Elevation of hypophysial portal concentrations of adrenocorticotropin secretagogues after fornix transection, Endocrinology, 125 (1989) 2881-2887.

31 Sapolsky, R.M., Krey, L.C. and McEwen. B.S., Glucocorticoidsensitive hippocampal neurons are involved in terminating the adrenocortical stress response, Proc. Natl. Acad. Sci. USA, 81 (1984) 6174-6177.

32 Sapolsky, R.M., McEwen, B.S. and Rainbow, T.C., Quantitative autoradiography of $[3 \mathrm{H}]$ corticosterone receptors in rat brain, Brain Res., 271 (1983) 331-334.

33 Sawchenko, P.E., Evidence for a local site of action for glucocorticoids in inhibiting CRF and vasopressin expression in the paraventricular nucleus, Brain Res., 403 (1987) 213-224.

34 Sawchenko, P.E. and Swanson, L.W., The organization of forebrain afferents to the paraventricular and supraoptic nuclei of the rat, J. Comp. Neurol., 218 (1983) 121-144.

35 Slusher, M.A., Effects of cortisol implants in the brainstem and ventral hippocampus on diurnal corticosteroid levels, Exp. Brain Res., 1 (1966) 184-194.

36 Sousa, R.J., Tannery, N.H. and Lafer, E.M., In situ hybridization mapping of glucocorticoid receptor mussenger ribonucleic acid in rat brain, Mol. Endocrinol, 3 (1989) 481-94.

37 Swanson, L.W. and Cowan, W.M. Hippocampo-hypothalamic connections: origin in subicular cortex, not ammon's horn, Science, 189 (1975) 303-304.

38 Swanson, L.W. and Cowan, W.M. An autoradiographic study of the organization of the efferent connections of the hippocampal formation in the rat, J. Comp. Neurol., 172 (1977) 49-84,
39 Swanson, L.W. and Sawchenko, P.E., Hypothalamic integration: organization of the paraventricular and supraoptic nuclei, $A n n u$. Rev. Neurosci., 6 (1983) 269-324.

40 Szafarcyzk, A., Hery, M., Laplante, E., Ixart, G., Assenmacher, I. and Kordon, $C$., Temporal relationships between the circadian rhythmicity in plasma levels of pituitary hormones and in hypothalamic concentrations of releasing factors, Neuroendocrinology, 30 (1980) 369-376.

41 Uht, R.M., McKelvy, J.F., Harrison, R.W. and Bohn, M.C., Demonstration of glucocorticoid receptor-like immunoreactivity in glucocorticoid-sensitive vasopressin and corticotropin-releasing factor neurons in the hypothalamic paraventricular nucleus, $J$. Neurosci. Res., 19 (1988) 405-411.

42 Van Eekelen, J.A.M., Jiang, W., deKloet, E.R. and Bohn, M.C., Distribution of the mineralocorticoid and the glucocorticoid receptor mRNAs in the rat hippocampus, J. Neurosci. Res., 21 (1988) 88-94.

43 Watts, A.G. and Swanson, L.W., Diurnal variations in the content of preprocorticotropin-releasing hormotie messenger ribonucleic acids in the hypothalamic paraventricular nucleus of rats of both sexes as measured by in situ hybridization, Endocrinology, 125 (1989) 1734-1738.

44 Whitnall, M.H., Key, S. and Gainer, H., Vasopressin-containing and vasopressin-deficient subpopulations of corticotropin-releasing factor axons are differentially affected by adrenalectomy, Endocrinology, 120 (1987) 2180-2182.

45 Whitnall, M.H., Smyth, D. and Gainer, H., Vasopressin coexists in half of the corticotropin-releasing factor axons present in the cxternal zone of the median eminence in normal rats, Neuroendocrinolozy, 45 (1987) 420-424.

46 Wilson, M.M., Greer, S.E., Grter, M.A. and Roberts, L., Hippocampal inhibition of pituitary-adrenocortical function in female rats, Brain Res., 197 (1980) 433-441.

47 Wyss, J.M., Swanson, L.W. and Cowan, W.M., The organization of the fimbria, dorsal fornix and ventral hippocampal commissure in the rat, Anat. Embryol. (Berlin), 158 (1980) 303-316.

48 Young, E.A., and Akil, H., Corticotropin-releasing factor stimulation of adrenocorticotropin and B-endorphin release: effects of acute and chronic stress, Endocrinology, 117 (1985) 23-30. 